For presentation at the IUTAM Symposium

"Innovative Computational Methods for Fracture and Damage"

Dublin, Ireland, June 30 - July 5, 1996.

\title{
Treatment of Anisotropic Damage Development within a Scalar Damage Formulation ${ }^{\#}$
}

\section{K.S. Chan ${ }^{1, *}$, S.R. Bodner ${ }^{1,2}$, D.E. Munson ${ }^{3}$}

1 Southwest Research Institute, San Antonio, TX 78238, U.S.A.

\section{OSTI} 2 Permanent address: Technion, Dept. of Mech. Eng., Haifa, Israel.

3 Sandia National Laboratories, Albuquerque, NM 87185, U.S.A.\#

* corresponding author

\begin{abstract}
This paper is concerned with describing a damage mechanics formulation which provides for non-isotropic effects using a scalar damage variable. An investigation has been in progress for establishing the constitutive behavior of rock salt at long times and low to moderate confining pressures in relation to the possible use of excavated rooms in rock salt formations as repositories for nuclear waste. An important consideration is the effect of damage manifested principally by the formation of shear induced wing cracks which have a stress dependent orientation. The analytical formulation utilizes a scalar damage parameter, but is capable of indicating the non-isotropic dependence of inelastic straining on the stress state and the confining pressure. Also, the equations indicate the possibility of volumetric expansions leading to the onset of tertiary creep and eventually rupture if the damage variable reaches a critical value.
\end{abstract}

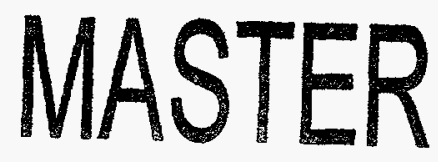

\# Work supported by U.S. Department of Energy (DOE), Contract No. DE-AC04-94AL85000 \#\# A U.S. DOE Facility 


\section{Introduction}

The concept of damage in the continuum sense as a load history dependent variable that leads to "softening" of the material was introduced by Kachanov (1958) almost 40 years ago. A physically based, and all encompassing definition of continuum damage has been elusive, although most investigators tend to regard geometrical discontinuities such as microcracks and voids as the main example. Such a restrictive definition of damage excludes imperfections in the crystalline lattice such as dislocations, but the definition is useful for examining the behavior of brittle and quasi-brittle materials.

Kachanov (1958) and later Rabatnov (1969) considered damage to be a scalar field quantity. An important application of their work and also of more recent investigations was the demonstration of the direct relation between damage development and tertiary creep of metals at high temperatures, which is somewhat similar to that of salt. However, the use of a simple scalar representation of damage has been criticized since it fails to indicate the directional nature of the damage associated with microcracks in the more brittle materials, e.g. Krajcinovic and Mastilovic (1995). Second and fourth order tensors are therefore recommended for that purpose particularly for the determination of the anisotropic effective moduli influenced by damage.

Nevertheless, a considerable amount of useful information of the effect of microdefects on the macro-response of rock salt, a quasi-brittle material, can be obtained based on a scalar representation of damage. This information consists of the non-isotropic and pressure dependent creep deformations and the conditions of failure. The analytical approach has been developed by the present authors and associates over the past five years in a program sponsored by the U.S. Department of Energy at the Sandia National Laboratories. The main interest of the program was to formulate constitutive equations, referred to as the Multimechanism Deformation Coupled Fracture (MDCF) model, and failure criteria for rock salt at long times under low and moderate confining pressures. Numerical techniques were also developed to determine the long time behavior of rock salt structures that could possibly be used as repositories for nuclear waste.

\section{Formulation of Constitutive Equations}

\section{a. Inelastic Flow due to Creep Damage Development}

A set of isotropic constitutive equations for creep of undamaged rock salt was developed by Munson and Dawson (1984) based on dislocation mechanisms. As such, the equations do not indicate pressure dependence and anisotropy of inelastic straining or volume changes.

Consideration of damage in the material equations consists, in part, of introducing a scalar damage parameter $\omega$ as a "softening" internal variable with an evolution equation for its development. Also, generation of damage is assumed to lead directly to additional inelastic straining and dilatancy. This effect is treated analytically by introducing a power-conjugate equivalent stress measure which depends on the current principal stress components, and a 


\section{DISCLAIMER}

Portions of this document may be illegible in electronic image products. Images are produced from the best available original document. 


\section{DISCLAMMER}

This report was prepared as an account of work sponsored by an agency of the United States Government. Neither the United States Government nor any agency thereof, nor any of their employees, makes any warranty, express or implied, or assumes any legal liability or responsibility for the accuracy, completeness, or usefulness of any information, apparatus, product, or process disclosed, or represents that its use would not infringe privately owned rights. Reference herein to any specific commercial product, process, or service by trade name, trademark, manufacturer, or otherwise does not necessarily constitute or imply its endorsement, recommendation, or favoring by the United States Government or any agency thereof. The views and opinions of authors expressed herein do not necessarily state or reflect those of the United States Government or any agency thereof. 
corresponding equivalent inelastic strain rate measure which, through a kinetic equation, is a function of the associated stress measure, temperature, and internal variables. If the stress measure used in the kinetic equation differs from that in the flow law for determination of the direction of inelastic straining, then the formulation is referred to as "non-associated" which can be relevant for an accurate description of rock salt, Chan et al. (1994). It was found necessary to distinguish between the stress measures of shear damage, $\sigma_{\mathrm{eq}}^{\omega_{\mathrm{s}}}$, and that of maximum tensile stress, $\sigma_{\mathrm{eq}}^{\omega_{\mathrm{t}}}$, since the nature of the stress leads to different geometries of microcracking and corresponding straining. The kinetics of damage development were also different for shear and tensile loading conditions. The power-conjugate stress measure operates as a flow potential so that the total inelastic strain rate, with the effects of damage development, could be expressed as

$$
\dot{\varepsilon}_{\mathrm{ij}}^{\mathrm{I}}=\frac{\partial \sigma_{\mathrm{eq}}^{\mathrm{c}}}{\partial \sigma_{\mathrm{ij}}} \dot{\varepsilon}_{\mathrm{eq}}^{\mathrm{c}}+\frac{\partial \sigma_{\mathrm{eq}}^{\omega_{\mathrm{s}}}}{\partial \sigma_{\mathrm{ij}}} \dot{\varepsilon}_{\mathrm{eq}}^{\omega_{\mathrm{s}}}+\frac{\partial \sigma_{\mathrm{eq}}^{\omega_{\mathrm{t}}}}{\partial \sigma_{\mathrm{ij}}} \dot{\varepsilon}_{\mathrm{eq}}^{\omega_{\mathrm{t}}}
$$

where $\sigma_{\text {eq }}^{\mathrm{c}}$ is the equivalent stress measure for creep corresponding to the Munson-Dawson equations (1984) with the inclusion of the damage parameter as a softening effect.

Eq. (1) indicates a directional dependence of the inelastic strain rate on the stress state through the derivatives of the equivalent stress measures with the stress components. Formulation of the appropriate expressions for the stress measures should be governed by the physics of the processes by which straining develops from the generation of damage. In the case of damage due to shear, wing cracks occur at the tips of the microcracks induced by slip and it is these wing cracks that promote the additional strains, Fig. 1 . The expression for $\sigma_{\mathrm{eq}}^{\omega_{\mathrm{s}}}$ consists of a term for damage generation, namely, the maximum shear stress which would be the maximum difference of principal stresses, $\sigma_{1}-\sigma_{3}$, and a term for suppression of damage development and ensuing creep due to the confining pressure P. A tensile principal stress would enhance damage growth with consequent straining so that $\sigma_{\text {eq }}^{\omega_{t}}$ consists only of the tensile stress component multiplied by a constant. The formulation by means of Eq. (1) therefore includes non-isotropy and pressure dependence of inelastic straining as well as volumetric expansion under non-hydrostatic triaxial compressive loading. Details of the procedure for simulating tertiary creep tests are given in Chan et al. $(1992,1994)$. In these simulations, the material constants appearing in the governing equations were obtained by fitting the predictions to a limited set of test results. An example of the calculated and corresponding test results are shown in Fig. 2, from Chan et al. (1994).

Part of the formulation is the evolution equation for damage development. This follows the general form used by most investigators in which the rate of damage is a function of damage multiplied by a function of stress which contains the equivalent stress measures for shear and tensile damage used in the kinetic equations for the equivalent strain rates. Again, the details are 
given in Chan et al. (1992, 1994, 1996a).

It is noted that the procedure described above utilizes the coordinates for the current principal stress state and not coordinates fixed in the material. This provides for coordinate invariance as well as for numerical convenience. Calculated creep deformations in the current principal stress directions could be translated incrementally to bodily fixed coordinates for nonproportional stress histories. Within this context, treating damage as a second or fourth order tensor appears to be complicated and not necessarily more accurate for the calculation of inelastic strains and deformations.

\section{b. Recovery and Healing of Damage}

Recovery and healing of damage developed in rock salt would be expected to occur under hydrostatic pressure and moderate to high temperatures. These conditions would lead to the closure of wing cracks and voids and at least partial merging of crack surfaces by a sintering like process. Since the microcracks induced by the prior loading would have directional characteristics, the straining associated with damage recovery and healing would not be isotropic. To account for recovery and healing strain rates, an additional term is added to eq. (1),

$$
\dot{\varepsilon}_{\mathrm{ij}}^{\mathrm{h}}=\frac{\partial \sigma_{\mathrm{eq}}^{\mathrm{h}}}{\partial \sigma_{\mathrm{ij}}} \dot{\varepsilon}_{\mathrm{eq}}^{\mathrm{h}}
$$

where $\sigma_{\mathrm{eq}}^{\mathrm{h}}$ is the equivalent stress measure associated with the generation of healing strains and $\dot{\varepsilon}_{\text {eq }}^{\mathrm{h}}$ is the equivalent healing strain rate measure.

A simple form that accounts for the anisotropy of straining due to healing is,

$$
\sigma_{\text {eq }}^{\mathrm{h}}=\frac{1}{3}\left(\mathrm{I}_{1}-\mathrm{B} \sigma_{1}\right) \geq 0
$$

where $I_{1}$ is the first stress invariant, $B$ is a constant, and $\sigma_{1}$ is the maximum principal stress with compression being positive. For hydrostatic compression, all the terms in eq. (1) become zero, since creep and formation of microcracks would not occur, while eq. (3) would be nonzero. It would also be non-zero for compressive stress states other than hydrostatic. In the case of a cylindrical specimen under hydrostatic compression, eqs. (2) and (3) lead to

$$
\left(\dot{\varepsilon}_{11} / \dot{\varepsilon}_{22}\right)=1-\mathrm{B}
$$

for the ratio of axial to lateral strain rates.

Tests of the healing of pre-damaged cylindrical specimens indicate that the actual strain rate ratio is bilinear so that two different mechanisms, each with a different value of $B$, appear to be 
operating during the healing process. Plots of changes of volumetric strain as a function of time also indicate that one mechanism acts at short times and another at longer times. For each of these mechanisms, the equivalent strain rate measure $\dot{\varepsilon}_{\mathrm{eq}}^{\mathrm{h}}$ can be represented by a first order kinetic equation and a characteristic time constant. Details of the analysis are given in Chan et al. (1995).

From the physical viewpoint, the initial short time mechanism for which $B>1$ at all test temperatures could be related to the closure of open wing cracks aligned in the axial direction with consequent axial extension. For the second longer time mechanism, $B=1$ for all the tests indicating no axial straining during that stage of the healing process. Volume change still occurs for the second mechanism which could correspond to the merging of the surfaces of axially aligned cracks. A plot of measured strain changes during the healing process and corresponding analytical predictions are shown in Fig. 3 , from Chan et al. (1995). It is noted in this example that lateral and volumetric dimensions reduce during the healing process while the axial dimension initially increases and then remains constant. The non-isotropy of the actual healing process seems to be reasonably well represented by the analytical model.

In addition to generating straining, healing of damage would reduce the amplitude of the damage variable. A damage healing term therefore needs to be added to the evolution equation for damage; such a term was proposed by Brodsky and Munson (1994).

Tests were also performed on the changes in the ultrasonic wave speeds during the healing process which were then compared to the original velocity of the undamaged material. Velocity measurements were taken both parallel and perpendicular to the axis of cylindrical specimens. At $70^{\circ} \mathrm{C}$, the changes in the reduced velocities with time of healing showed the same characteristics in both directions, Fig. 4 in Chan et al. (1995). At $20^{\circ} \mathrm{C}$, however, the tests showed a definite difference indicating the increased effect of damage in reducing the wave velocity in the perpendicular direction, i.e. normal to the induced wing cracks, Fig. 4. A simplified analytical model for damage reduced wave velocity was developed based on considering damage as a scalar. Whereas the analysis provided reasonable results for wave speed recovery parallel to the axis, Fig. 4, it could not account for the anisotropic effect of damage on the wave velocity in the perpendicular direction.

A more sophisticated analytical treatment of damage as a second order tensor would be straightforward for the case of fixed principal stress and damage axes that coincide with the geometrical axis of cylinders which are subjected to hydrostatic pressure. On such a basis, better agreement in both directions could have been achieved for the case shown in Fig. 4. However, damage effects are particularly important in structures subjected to non-proportional loading histories for which the treatment of damage as a higher order tensor would be appreciably more complicated. 


\section{Creep Failure and Cleavage}

Similar to the early work of Kachanov (1958) and of Rabotnov (1969), the inclusion of damage effects in the governing equations for creep of rock salt can lead to tertiary creep and failure. For that to be possible at some unspecified time, the volumetric expansion and damage development rates should be positive which corresponds to a condition on the total stress measure. In the particular case of triaxial compression under which most tests have been performed, this condition can be expressed in terms of $\sqrt{J_{2}}$ and $I_{1}$, where $J_{2}$ is the second invariant of deviatoric stress and $\mathrm{I}_{1}$ is the first stress invariant. That relation, as shown in Fig. 5, from Chan et al. (1996a), agrees well with test data.

Elapsed times for the onset of tertiary creep and for failure are important parameters for engineering purposes. Comparisons of numerical simulations based on the MDCF model with test results indicate that the onset of tertiary creep generally correlated with an accumulated damage value of 0.015 and that failure occurred at a damage value of about 0.15 . Of various possible criteria for determining creep failure times, the one using a critical damage value of 0.15 proved to be the most consistent with test results, Chan et al. (1996a). The time to rupture increased with increasing confining pressures. At a confining pressure greater than $5.8 \mathrm{MPa}$, damage development was almost totally suppressed and the time to rupture became extremely large ( $>10^{8}$ days), as shown in Fig. 6 .

Another possible failure mechanism of rock salt is by cleavage which has to be examined by the methods of fracture mechanics. This has been the subject of a recent investigation which has been reported by Chan et al. (1996b). One result of the fracture mechanics analysis is that unstable wing crack extension could occur only in the presence of a tensile stress acting normal to the wing cracks. Combinations of stress components that govern the various possible failure modes are indicated on fracture mechanism maps in Chan et al. (1996b).

An interesting subject is the relationship of elastic moduli reductions due to damage development to the onset of failure. There have been extensive investigations on the reductions of elastic moduli due to the presence of microcracks. These studies have generally been based on particular forms of cracks and their geometrical distribution in the material, i.e. whether in regular arrays or random and whether or not the cracks are interacting. The concept of a crack density function has been found useful in these analyses. An obvious result is that a preferred orientation of cracks leads to non-isotropy and anisotropic reduced elastic moduli. A thorough review of investigations on this subject up to 1992 was prepared by Kachanov (1992).

The matter of whether a correlation exists between the tendency to fracture of a brittle solid and the change of effective reduced moduli influenced by cracking was raised by Kachanov (1992). Such a correlation would be necessary if progression toward fracture could be monitored by the changes of elastic moduli. Kachanov (1992) notes that failure by cleavage is a local effect controlled by the local stress state, the details of the crack geometry, and the fracture toughness of the material. As such, the tendency to cleavage failure would not be expected to necessarily correlate with reductions in elastic moduli which are an overall 
volumetric average effect. In the case of failure by creep rupture, however, which was not discussed by Kachanov (1992), the correlation does appear to exist since both could be described, at least as an approximation, as dependent on the same scalar damage variable.

\section{Summary}

A damage mechanics formulation that provides for various non-isotropic effects using a scalar damage variable is presented. The formulation is capable of indicating the non-isotropic dependence of inelastic straining on the stress state and the confining pressure. Capabilities and limitations of the model are illustrated with numerical calculations for rock salt. 


\section{References}

Brodsky, N.S. and Munson, D.E. (1994): Thermomechanical damage recovery parameters for rock salt from the waste isolation pilot plant. In: Nelson, P.P. and Laubach , S.E. (eds). Proc. First N. Amer. Rock Mech. Symp.: Brookfield, VT: Balkema. pp. 731-738.

Chan, K.S., Bodner, S.R., Fossum, A.F. and Munson, D.E. (1992): A constitutive model for inelastic flow and damage evolution in solids under triaxial compression. Mech. Mat. 14, $1-14$.

Chan, K.S., Brodsky, N.S., Fossum, A.F., Bodner, S.R. and Munson, D.E. (1994): Damage-induced nonassociated inelastic flow in rock salt. Int. J. of Plasticity. 10, 623-642.

Chan, K.S., Bodner, S.R., Fossum, A.F. and Munson, D.E. (1995): Constitutive representation of damage development and healing in WIPP salt. In: Proceedings of the 35th U.S. Symposium on Rock Mechanics. Daemen, J.J.K. and Schultz, R.A. (eds). Brookfield, VT: Balkema. pp. 485-490.

Chan, K.S., Bodner, S.R., Fossum, A.F. and Munson, D.E. (1996a): A damage mechanics treatment of creep failure in rock salt. Int. J. Damage Mechanics. (In press).

Chan, K.S., Munson, D.E., Fossum, A.F. and Bodner, S.R. (1996b): Cleavage and creep rupture of rock salt. Acta Metall. et Mater. (In press).

Kachanov, L.M. (1958): On creep rupture time. Izv. Acad. Nauk, SSR, Otd. Techn. Nauk, $8,26-31$.

Kachanov, M. (1992): Effective elastic properties of cracked solids: Critical review of some basic concepts. Appl. Mech. Rev. 45, 304-335.

Krajcinovic, D. and Mastilovic, S. (1995): Some fundamental issues of damage mechanics. Mech. Mat. 21, 217-230.

Munson, D.E. and Dawson, P.R. (1984): Salt constitutive modeling using mechanism maps. In: Proc. First Conference on the Mechanical Behavior of Salt. Rockport, MA: Karl Distributors. 717-737.

Rabotnov, Y.N. (1969): Creep problems in structural members. North-Holland, Amsterdam. 
Legends to Figures

Figure 1. General fracture pattern under compression.

Figure 2. Experimental creep curves of WIPP salt tested at $\sigma_{1}-\sigma_{3}=25 \mathrm{MPa}$ under a confining pressure, $\mathrm{P}$, of 1 or $15 \mathrm{MPa}$ with comparison to model calculations. [From Chan et al. (1994).]

Figure 3. Comparison of calculated and measured volumetric, lateral, and axial strains recovered during damage healing of WIPP salt under a hydrostatic pressure of $15 \mathrm{MPa}$ at $70^{\circ} \mathrm{C}$.

Figure 4. Comparison of calculated and measured wave velocities during healing of salt at $20^{\circ} \mathrm{C}$.

Figure 5. Calculated dilatational zone boundary compared to experimental data compiled by Van Sambeek et al. (1993), and Chan et al. (1996a).

Figure 6. Comparison of calculated and measured creep rupture times for WIPP salt as a function of confining pressure. Creep rupture was taken to occur at $\omega=0.15$ in the model calculations. [From Chan et al. (1996a)] 


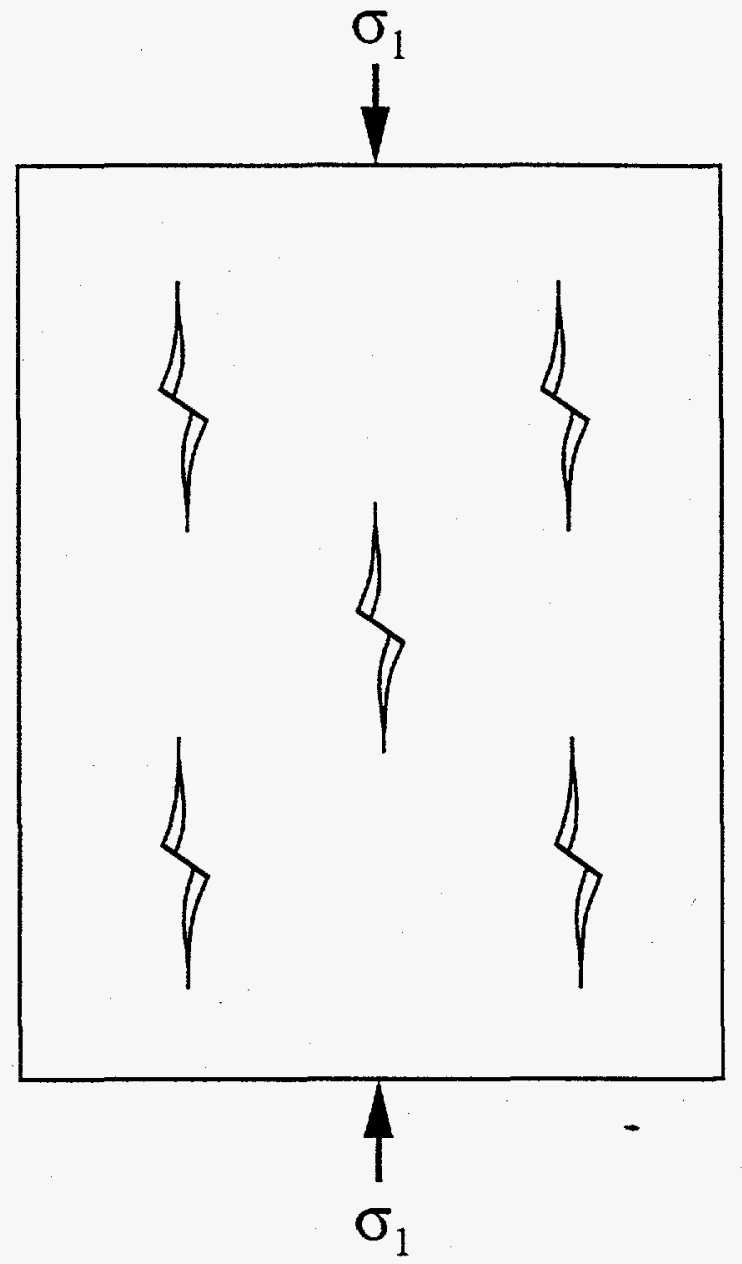

Fig.1 General fracture pattern under compression. 


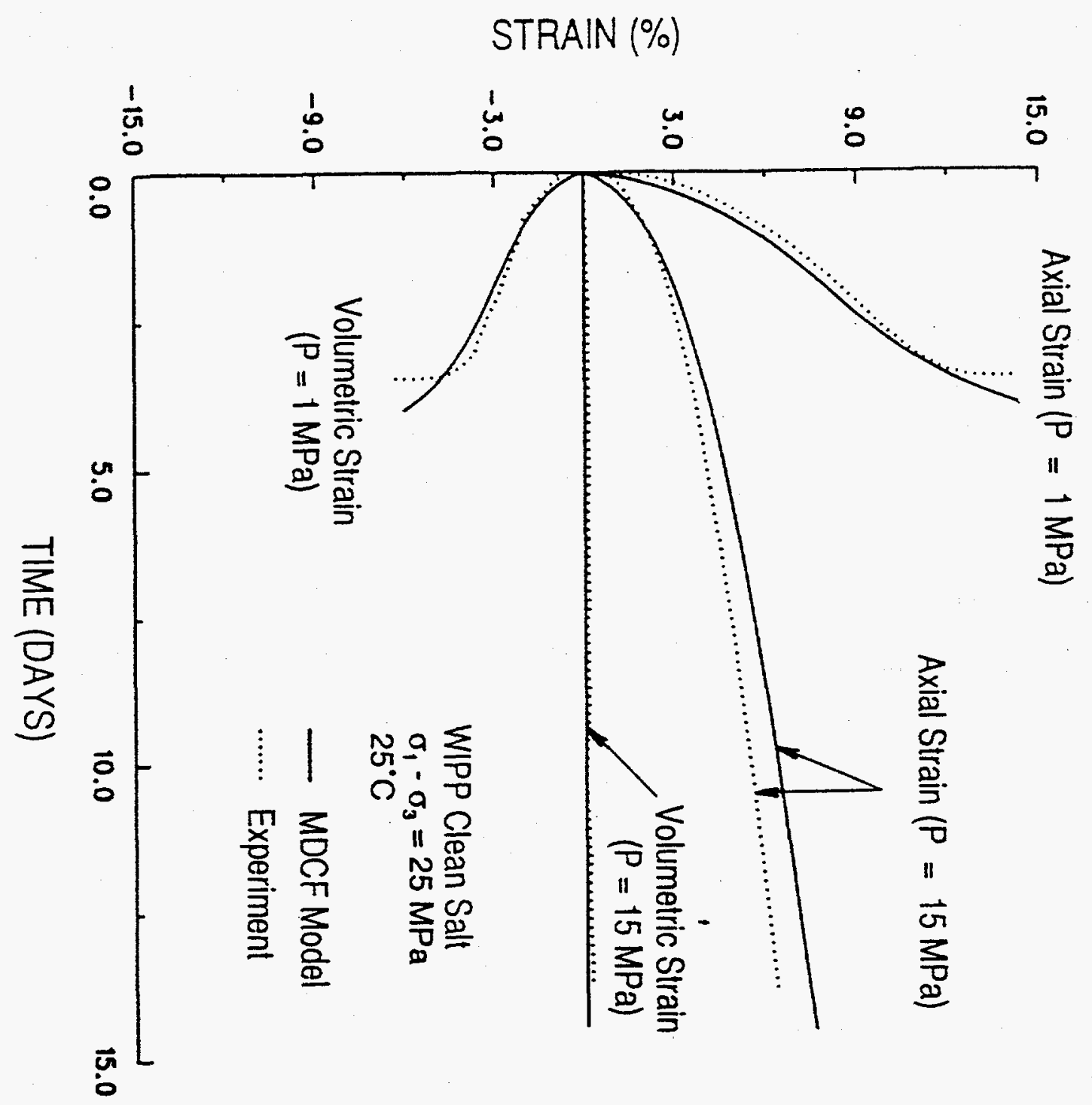




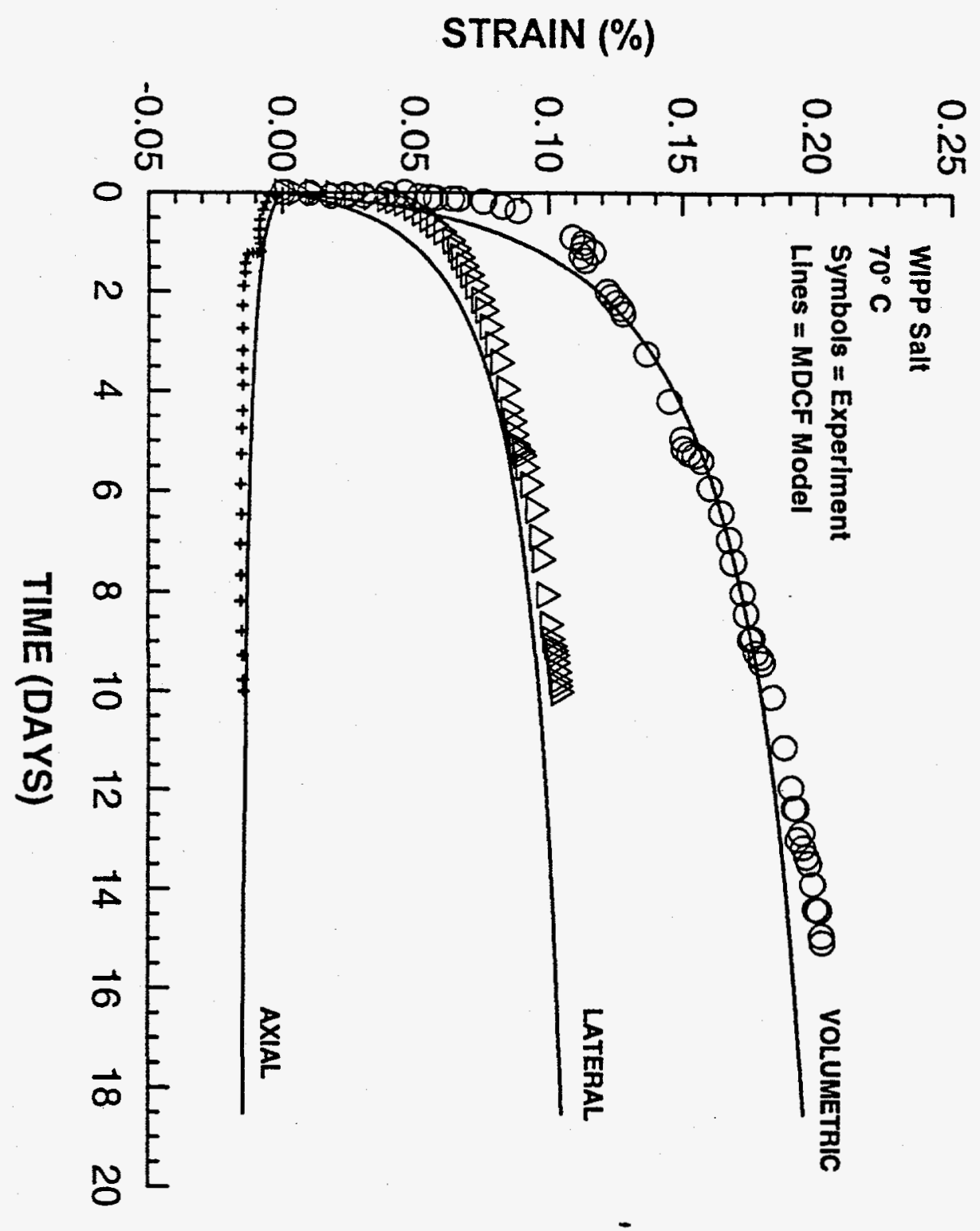



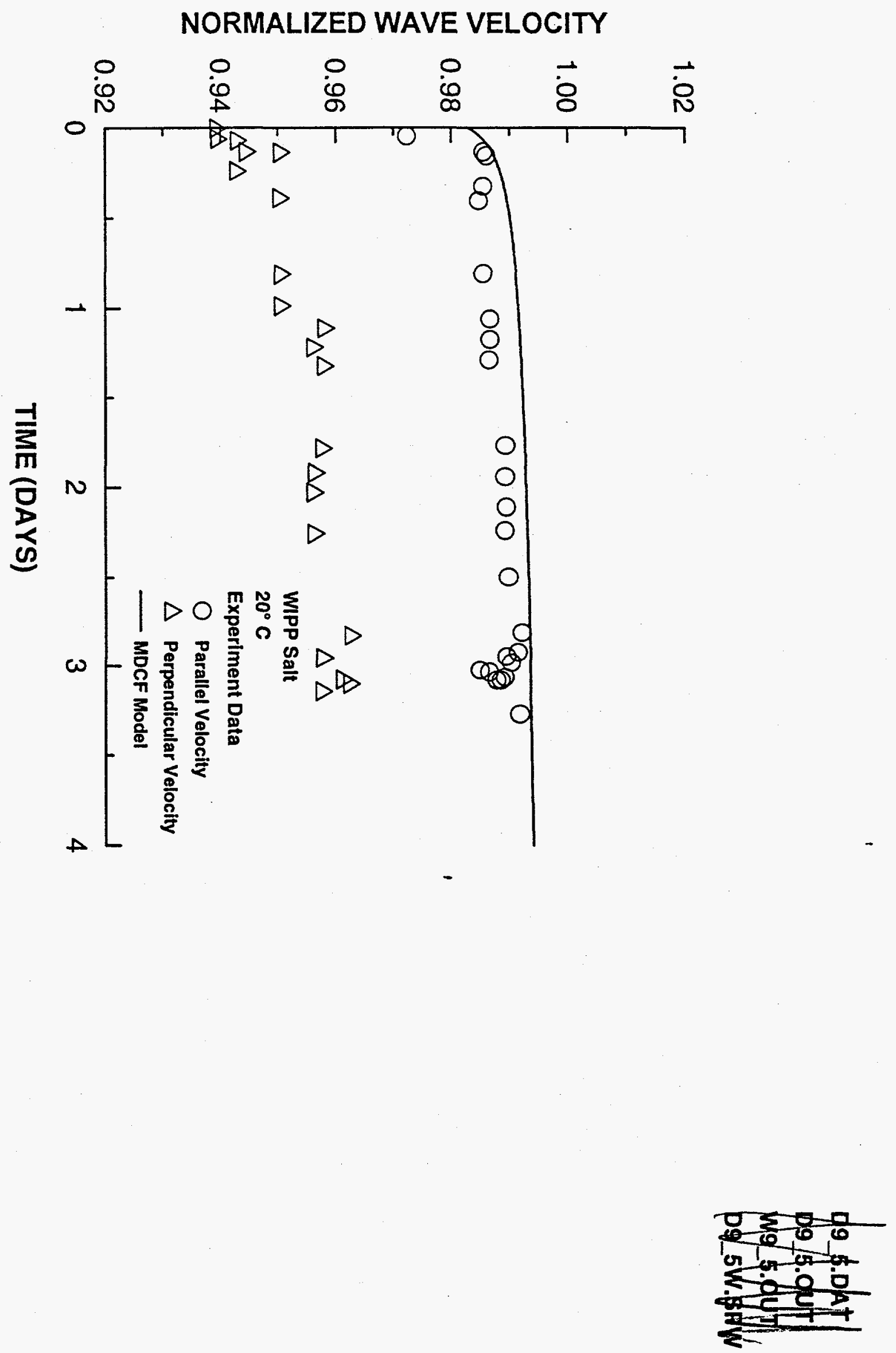


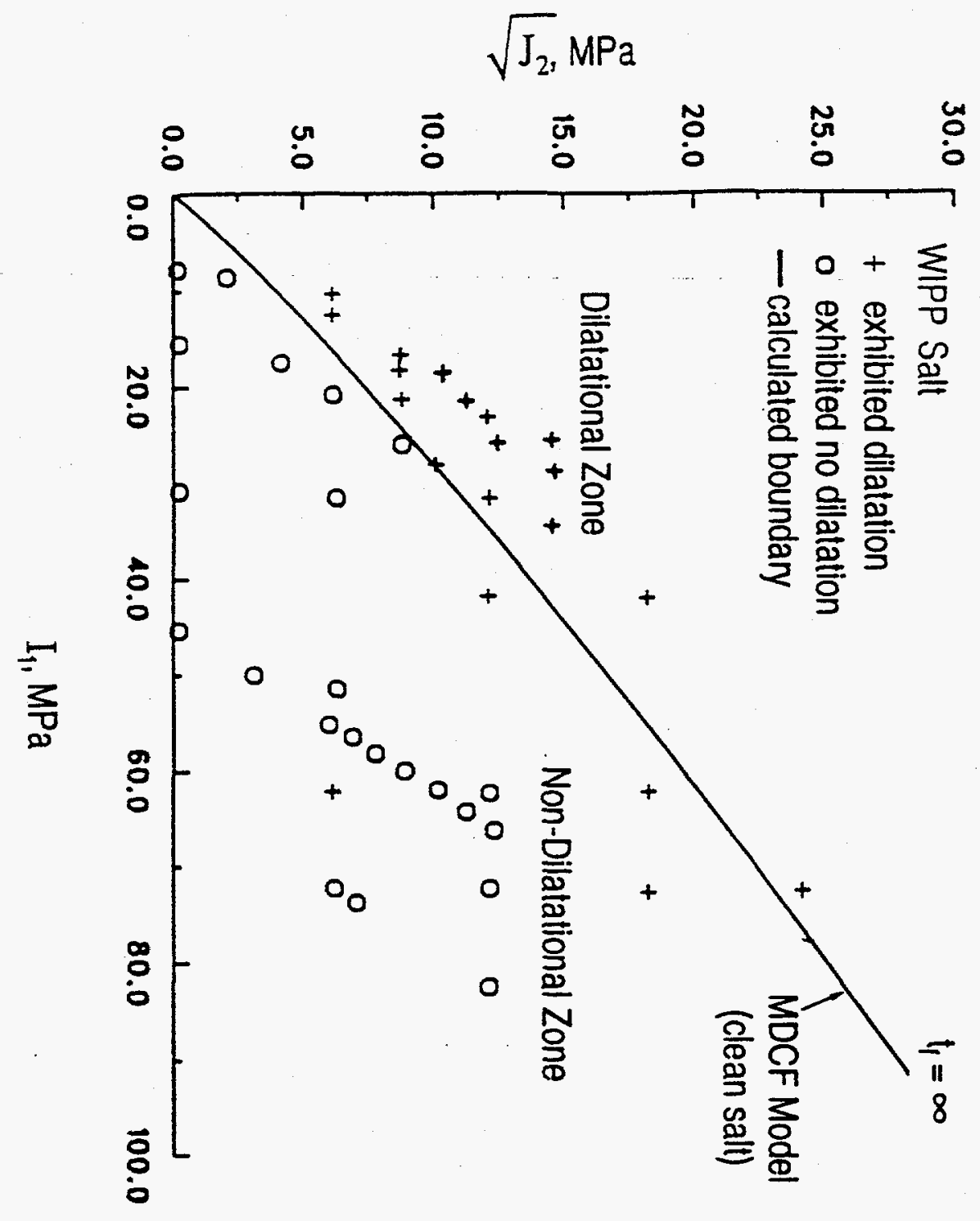




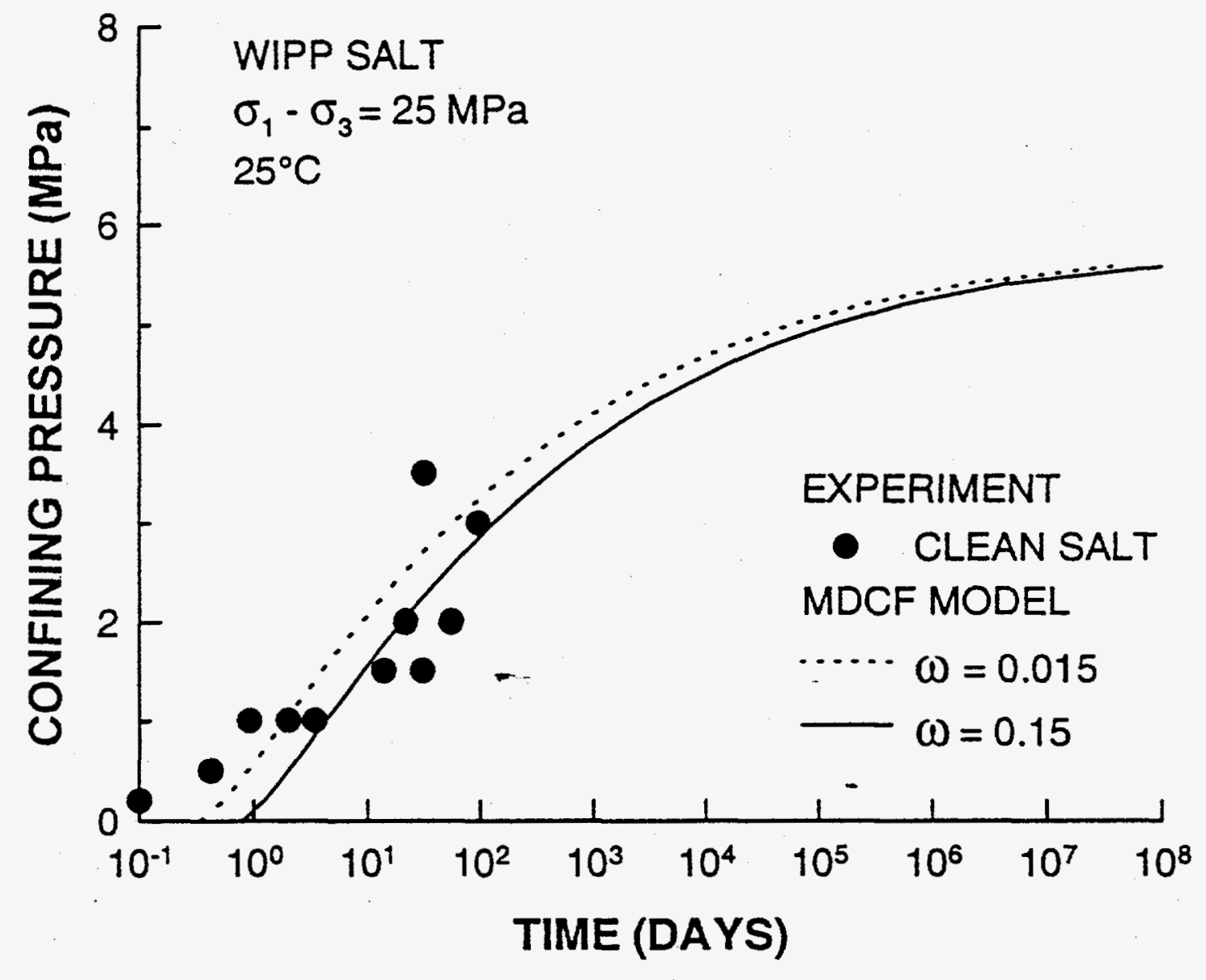

